\title{
Singuagens
}

\section{DISCURSO PUBLICITÁRIO E IDENTIDADE REGIONAL: UM OLHAR PARA AS MARCAS DE GAUCHIDADE NA PEÇA PEPSITCHÊ}

\author{
Nêmora Luiza Gehring Schreiner (UFSM) \\ Andrea Ad Reginatto (UFSM)
}

RESUMO: Há um crescente interesse pela cultura e identidade regional local nos textos publicitários. Assim, este artigo tem como objetivo verificar de que forma a expressão tchê reitera a identidade do possível consumidor da marca Pepsi, considerando as práticas sociais e discursivas. Além disso, pretende demonstrar que as escolhas lexicais propiciam uma imagem do produto próxima à imagem do possível consumidor. A análise foi construída a partir da peça publicitária PepsiTchê e utilizou como abordagem a pesquisa de natureza bibliográfica. Para desenvolver a investigação, foi realizado um levantamento através do hotsite dedicado à publicidade da PepsiTchê, material de cunho publicitário exclusivo para consumidores gaúchos. Essa metodologia articula contribuições advindas dos conceitos de gênero do discurso, acento de valor, intertextualidade e dialogismo, a partir dos estudos do Círculo de Bakhtin. Como resultados da pesquisa compreendemos que as escolhas dos elementos linguísticos, no gênero discurso publicitário, contribuem com as relações dialógicas estabelecidas entre a marca e o possível consumidor e delimitam os acentos valorativos sobre a marca/produto.

PALAVRAS-CHAVE: Discurso publicitário. Acento de valor. Identidade.

ABSTRACT: There is a growing interest in regional culture and identity in advertising. There fore, this article aimsto verify how the expression tchê reiterates the identity of the possible consumer of Pepsi, considering social and discursive practices. Furthermore, it intends to demonstrate that lexical choices provide animage of the product close to the image of the possible consumer. The analysis was constructed from the advertising piece PepsiTchê and used bibliographicre search. In order to develop there search itself we carried out a survey through the hotsite dedicated to the advertising of PepsiTchê, exclusive publicity for consumers from Rio Grande do Sul. This methodo logy articulates contributions coming from the concepts of genre of discourse, evaluative accentuation, intertextuality and dialogism from the studies of the Bakhtin Circle. As results of there search we understand that the choices of the linguistic elements in theadvertisinggenrecontributetothedialogicalrelationsestablishedbetweenthebrand (Pepsi), as well as the possible consumer, and delimit the evaluative accentuation on the brand/product.

KEYWORDS: Advertisinggenre. Identity. Evaluativeaccentuation.

\section{INTRODUÇÃO}
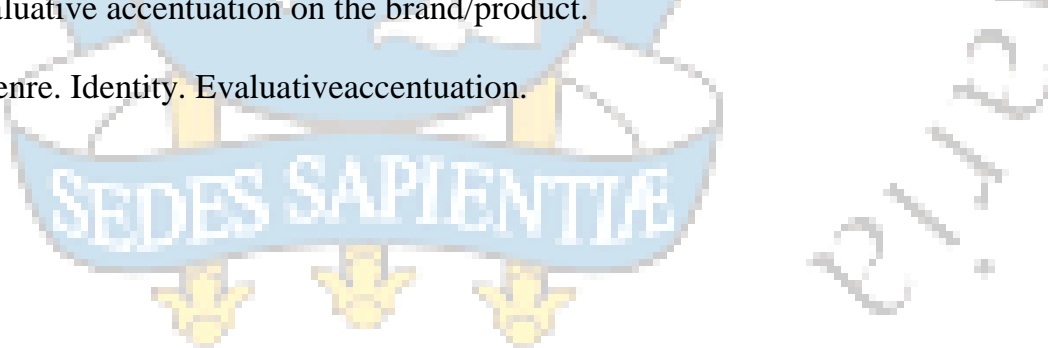

Os diversos meios de comunicação com os quais temos contato diariamente são um difusor de inúmeras campanhas publicitárias dentre as quais, como espectadores, somos atraídos ou não para uma possível compra. Nesse sentido, observamos um crescente interesse pela cultura e identidade local por parte dos discursos circulantes na esfera midiática, especialmente em textos publicitários, pois cada vez mais fazem uso de marcas locais como estratégia persuasiva. No Rio Grande do Sul, por exemplo, são amplamente utilizadas 


\section{S Linguagens}

expressões do vocabulário regional gaúcho na produção de sentido nos discursos publicitários.

Diante desse contexto, o problema de pesquisa que norteia as buscas do presente estudo está assim definido: De que forma a expressão tchê reitera a identidade do possível consumidor da marca de refrigerante Pepsi, levando em conta as práticas sociais e discursivas? Considerando aqui a peça publicitária PepsiTchê $\hat{}^{1}$, que demonstra a intenção de criar um vínculo emocional e identitário entre a marca e os indivíduos nascidos no Rio Grande do Sul, cabe ressaltar que essa prática discursiva vem relacionada justamente ao orgulho em ser gaúcho e o grande apego às tradições.

Desse modo, o artigo visa demonstrar que as escolhas dos elementos linguísticos propiciam uma imagem do produto próxima à imagem do possível consumidor. Para isso é preciso analisar como se constitui o discurso publicitário, tendo em vista as práticas sociais, assim como demonstrar que as escolhas lexicais interferem na força argumentativa do discurso publicitário e, ainda, refletir sobre as práticas da leitura e compreensão de discursos.

Os anúncios publicitários estão em todo lugar, fazem parte do nosso cotidiano e contribuem para a formação de nossa cultura, pois podem estimular ou minar determinado aspecto cultural. É importante lermos e analisarmos os anúncios publicitários para compreender o sentido por ele produzido, visto que o discurso publicitário se baseia na linguagem do seu público alvo e escolhe determinados elementos lexicais para explorar sua força argumentativa.

O presente trabalho está estruturado em cinco seções, sendo esta a primeira, introdutória, que busca contextualizar o tema e a problemática. A segunda é dedicada ao referencial teórico que embasa a condução deste estudo. A metodologia de pesquisa está apresentada na quarta seção, seguida da análise do corpus em estudo. Por fim, são expostas as considerações finais.

\section{CONSIDERAÇÕES SOBRE DISCURSO E ESFERA PUBLICITÁRIA}

\footnotetext{
${ }^{1}$ Peça publicitária em homenagem a Semana Farroupilha lançada em setembro de 2016, divulgada através do hotsite disponível em < http://www.pepsibrasil.com.br/tche/\# >.
}

Linguagens \& Cidadania, v. 19, jan./dez., 2017. 


\section{S Linguagens}

Ao lançar o olhar sobre os estudos que envolvem discurso e produção de sentido, buscamos as questões desenvolvidas pelo Círculo de Bakhtin, porque apontam para a ideia de que o discurso acontece na e pela interação, na linguagem em uso. Na intenção de interagir com o outro, nas diversas instâncias de comunicação, o discurso é a realização da linguagem, ou seja, na medida em que se usa a língua para se comunicar socialmente, passa-se a construir um discurso em que o enunciador determina suas intenções e suas posições a partir daquele que tem como interlocutor, $\mathrm{o}$ que possibilita conferir ao outro a intencionalidade do enunciador (BAKHTIN, 1997).

Assim, entendemos que os indivíduos interagem por meio da linguagem. Conforme Bakhtin, cada texto, cada enunciado, ou seja, cada discurso apresenta-se em contextos diferenciados e, ao diferenciar o uso concreto de cada discurso, deparamo-nos com o que o autor chamou de gêneros do discurso. Esses são mecanismos discursivos com os quais operamos em situações diversas, pois "a riqueza e a variedade dos gêneros do discurso são infinitas" (BAKHTIN, 1997, p. 279), considerando as múltiplas possibilidades de atuação da atividade humana. Nesse sentido, "cada esfera dessa atividade comporta um repertório de gêneros do discurso que vai diferenciando-se à medida que a própria esfera se desenvolve e fica mais complexa" (BAKHTIN, 1997, p. 279).

Partindo dessas considerações, voltamos o olhar para as questões em torno do discurso publicitário, uma vez que o tema desta pesquisa está centrado na análise de vozes que ecoam desta esfera discursiva. Nesse sentido, observamos que este tipo de discurso é revestido de características que têm como objetivo apresentar determinado produto/marca e estimular o seu consumo. Para uma maior interação com os indivíduos, possíveis consumidores, o discurso publicitário é constituído por enunciados, assim como o objeto do nosso estudo a PepsiTchê, em que os refrigerantes Pepsi se apropriam de uma marca linguística própria do gaúcho para, numa relação dialógica, aproximar-se do público que deseja atingir. Assim, é importante considerar a especificidade comunicativa do gênero publicidade e também as várias formas de apresentação (jornais, outdoor, vídeo, internet, etc.)

Considerando o tema deste estudo, é importante refletirmos sobre os momentos históricos, os quais ficam enraizados na cultura de um povo, no caso específico desta pesquisa, o povo do Rio Grande do Sul, o qual carrega em sua identidade a memória das batalhas e a luta campeira por meio das tradições, do modo de agir e falar. Para Bakhtin 


\title{
S Linguagens
}

(1997, p. 285), “os enunciados e o tipo a que pertencem, ou seja, os gêneros do discurso, são correias de transmissão que levam da história da sociedade à história da língua". Compreender esta relação nos auxilia no entendimento da prática discursiva proposto neste estudo, uma vez que é preciso

\begin{abstract}
reconhecer o gênero a que pertencem os textos e os gêneros que nele se articulam, descobrir a tradição das atividades em que esses discursos se inserem e, a partir desse diálogo com o objeto de análise, chegar ao inusitado de sua forma de ser discursivamente, à sua maneira de participar ativamente de esferas de produção, circulação e recepção, encontrando sua identidade nas relações dialógicas estabelecidas com outros discursos, com outros sujeitos (BRAIT, 2006, p. 13).
\end{abstract}

Nesse sentido, ao utilizar no discurso publicitário expressões usadas no cotidiano do gaúcho, temos o que Bakhtin (1997, p. 281) esclarece, em Estética da Criação Verbal ${ }^{2}$, como a incorporação do gênero do discurso primário (simples) pelo gênero do discurso secundário (complexo). Gêneros do discurso primário (simples) são "de todas as espécies, que se constituíram em circunstâncias de comunicação verbal espontânea” e, segundo o autor, “os gêneros secundários do discurso - o romance, o teatro, o discurso científico, o discurso ideológico, etc. - aparecem em circunstâncias de uma comunicação cultural, mais complexa e relativamente mais evoluída, principalmente escrita: artística, científica, sociopolítica". De acordo com os estudos bakhtinianos, é possível entender que, ao incorporar a fala do cotidiano sul-rio-grandense, os discursos estão envolvidos pela cultura do ser gaúcho e, deste modo, também o discurso publicitário, este visto como "gêneros secundários absorvem e transmutam" (BAKHTIN, 1997, p. 281) as expressões da fala cotidiana do gaúcho, implicando novas nuances a esse discurso.

Assim, constrói-se, então, uma relação dialógica entre os discursos. Conforme Fiorin (2006, p. 169), “a relação dialógica é uma relação (de sentido) que se estabelece entre enunciados na comunicação verbal". Considerando a interação entre interlocutores em um dado momento histórico e também dos sujeitos com a sociedade, o discurso toma forma e produz sentidos em dados contextos sociais. Por exemplo,

\footnotetext{
${ }^{2}$ Em 1979 é publicado Estética da Criação Verbal, que comporta, essencialmente os primeiros e últimos escritos de Mikhail Bakhtin.
}

Linguagens \& Cidadania, v. 19, jan./dez., 2017. 
a palavra fogo é completa, mas não suscita nenhuma resposta. Só quando adquire uma autoria e ganha um acabamento, transforma-se em enunciado, que denuncia uma situação de perigo e permite ser objeto de uma resposta. Sendo réplicas de um diálogo, os enunciados têm um destinatário, enquanto as unidades da língua não são dirigidas a ninguém (BAKHTIN, 1992 apud FIORIN, 2006, p. 169).

Ainda, essa relação entre discursos é constituída por muitas vozes, que os compõem, que se cruzam e se completam, conforme explica Bakhtin (1997, p. 290): “o ouvinte que recebe e compreende a significação (linguística) de um discurso adota simultaneamente, para com este discurso, uma atitude responsiva ativa: ele concorda ou discorda (total ou parcialmente), completa, adapta, apronta-se para executar, etc”. Desse modo, uma cadeia discursiva se organiza em torno da minha voz que está em constante união e intercâmbio com as demais vozes, portanto nosso discurso é repleto de outras vozes, e que, no ato de interlocução gerará atitudes responsivas.

De acordo com Bakhtin (1997, p. 291), certos gêneros do discurso desencadeiam “compreensão responsiva muda" ou "poderíamos dizer, de uma compreensão responsiva de ação retardada: cedo ou tarde, o que foi ouvido e compreendido de modo ativo encontrará um eco no discurso ou no comportamento subsequente do ouvinte". Notemos que muitos gêneros discursivos secundários, como o discurso publicitário, contam com esse tipo de compreensão ao expor seu discurso e esperam "uma resposta, uma concordância, uma adesão, uma objeção, uma execução, etc.” (BAKHTIN, 1997, p. 291).

Como parte integrante de uma relação dialógica, o enunciado proferido pelo locutor não constitui o primeiro enunciado; é a resposta a discursos anteriores, em que há um encadeamento das vozes, "um elo da cadeia complexa de outros enunciados" (BAKHTIN, 1997, p. 291). Contudo, Fiorin (2006, p. 178), refletindo sobre o pensamento bakhtiniano, afirma que não só de enunciados anteriores essa relação dialógica é constituída, mas também o que vem a partir do discurso, a resposta esperada que compõe o próprio discurso.

Considerando as questões sobre discurso, importa salientar que é por meio dele que o locutor tem sua intencionalidade exposta, ele tem algo a dizer, que "se realiza acima de tudo na escolha de um gênero do discurso" (BAKHTIN, 1997, p. 301), já que esta intenção "adapta-se e ajusta-se ao gênero escolhido" (p. 301). Deve-se considerar o tom que se adota ao discurso e qual relação deseja ser evocada, o "querer-dizer" do locutor passa a assumir um 


\section{S Linguagens}

sentido. Por isso, "o enunciado se caracteriza acima de tudo pelo conteúdo preciso do objeto do sentido [...] a relação valorativa com o objeto do discurso (seja qual for esse objeto) também determina a escolha dos recursos lexicais, gramaticais e composicionais do enunciado" (BAKHTIN, 1997, p. 308). Assim, ao escolher determinados recursos lexicais para compor o conteúdo do objeto de sentido do discurso, o locutor estabelece o que querdizer, o sentido dentro do discurso e, para que se estabeleça esse sentido, deve estar intrinsicamente ligado à realidade e às práticas sociais.

No discurso publicitário, tema de discussão deste estudo, estabelece-se um sentido ao enunciado quando este se relaciona a uma determinada realidade. Dessa forma, o contexto do enunciado cria uma espécie de relação entre o que o locutor quer-dizer e o sentido produzido pelo enunciado concreto. A peça publicitária PepsiTchê estabelece sentido em torno de uma expressão do vocabulário gaúcho, o tchê, que em variados contextos tem diversos significados, porém a relação se constrói com a significação do refrigerante. Assim, para Bakhtin, "escolhemos a palavra de acordo com sua significação que, por si só, não é expressiva e pode ou não corresponder ao nosso objetivo expressivo em relação com as outras palavras, isto é, em relação com o todo do nosso enunciado" (BAKHTIN, 1997, p. 311).

Entretanto, é na comunicação verbal viva que o enunciado produz sentido, de modo que a palavra não significa sozinha, mas encontra sentido na interação, na linguagem em uso, de acordo com as relações sociais. Ao relacionar uma expressão do vocabulário regional gaúcho com o refrigerante Pepsi, a anunciante busca maior proximidade com seu possível consumidor. A fim de entendermos a constituição do discurso publicitário, analisaremos a peça PepsiTchê, através do seu hotsite, a partir de orientações metodológicas específicas, descritas na próxima seção.

\section{PROCEDIMENTOS METODOLÓGICOS}

Considerando que o objetivo do presente estudo é demonstrar que as escolhas dos elementos discursivos propiciam uma imagem do produto próxima à imagem do possível consumidor, analisamos o discurso publicitário da peça PepsiTchê da marca de refrigerante Pepsi.

Linguagens \& Cidadania, v. 19, jan./dez., 2017. 


\section{Linguagens}

\subsection{A composição do material de análise}

Ao observar o uso de expressões próprias do vocabulário regional gaúcho nos discursos publicitários, surgiu o interesse de compreender o seu uso e suas intencionalidades diante das práticas sociais e discursivas. Assim, realizamos uma pesquisa, a fim de encontrar anúncios ou peças publicitárias com o uso das expressões típicas dos gaúchos. Na seleção do material, optamos pela peça publicitária PepsiTchê, lançada em setembro de 2016 em comemoração à Semana Farroupilha, e que conta com 13 latinhas do refrigerante Pepsi decoradas com histórias dos gaúchos. Para este estudo, consideramos o hotsite da peça publicitária PepsiTchê em que se destaca a expressão regional gaúcha tchê, conforme representado na Figura 1.

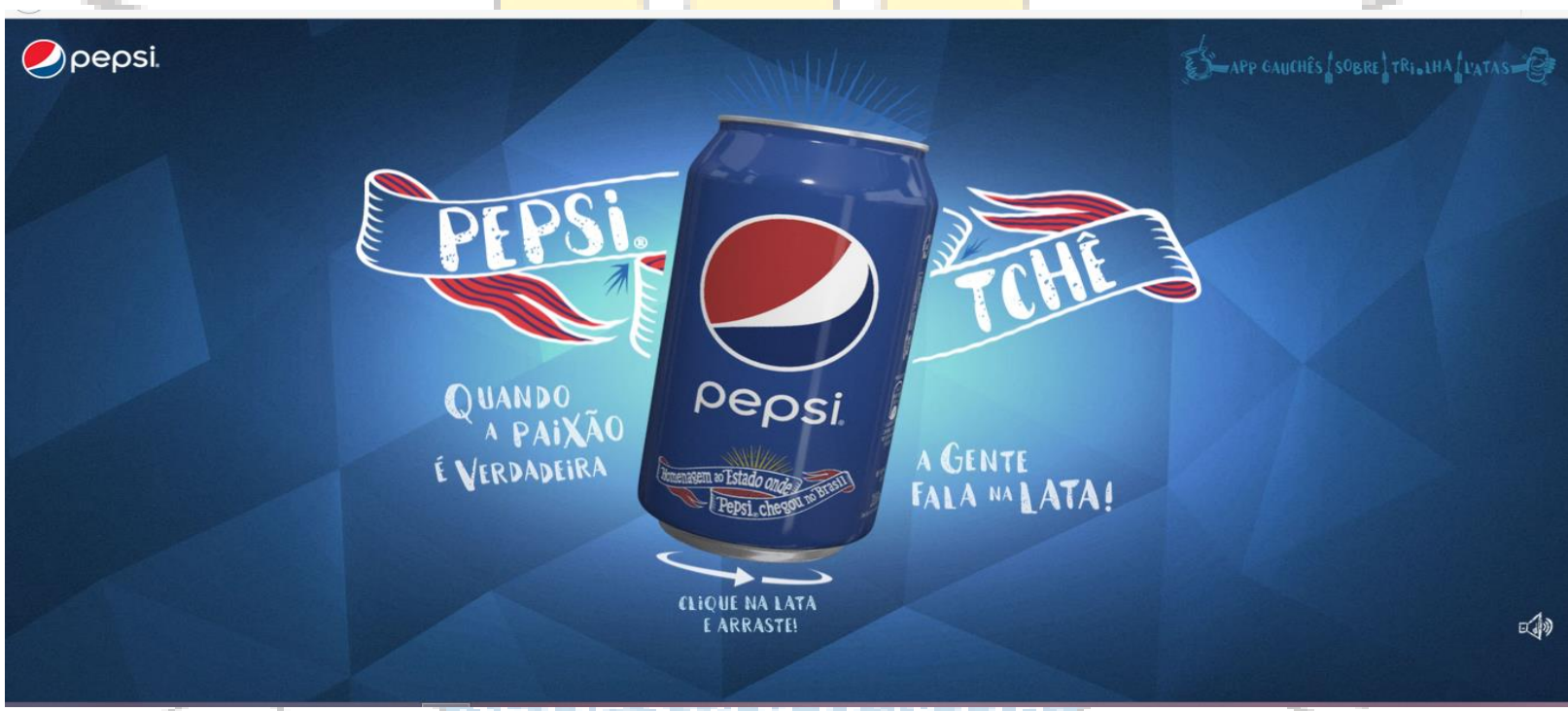

Figura 1 - Fonte: www.pepsibrasil.com.br/tche/\#

A pesquisa volta o olhar para a relação entre variáveis, por exemplo, a expressão tchê do vocabulário regional gaúcho e seu uso no discurso publicitário, considerando a construção da identidade do possível consumidor da marca de refrigerante Pepsi. A perspectiva dos procedimentos deste estudo é bibliográfica e a abordagem é qualitativa, pois busca analisar a produção de sentido da expressão tchê pelo possível consumidor do refrigerante, considerando a teoria/análise do gênero do discurso proposto pelo Círculo de Bakhtin (1997) e reforçado por Brait (2006) e Fiorin (2006).

Linguagens \& Cidadania, v. 19, jan./dez., 2017. 


\section{Singuagens}

\section{RESULTADOS E DISCUSSÃO}

A formação étnico-cultural do Rio Grande do Sul é diversa; temos influência da colonização portuguesa e espanhola, além dos índios que aqui já viviam, dos negros e dos imigrantes que vieram mais tarde (alemães, italianos e outros). A construção da identidade do gaúcho provém dessa diversidade e também dos acontecimentos históricos que foram importantes para moldar o povo do Rio Grande do Sul. Toda essa multiplicidade deixou suas marcas que o unificam culturalmente, a exemplo de expressões do vocabulário regional gaúcho, que são como marcas de identidade que fazem os gaúchos se identificarem, reconhecerem-se por essas expressões em uma relação de pertencimento social. Tais expressões são reconhecidas, pois elas indicam conhecimentos culturais compartilhados, e o destinatário compreende-as, partindo do princípio de que se identifica com o falar regional de seu interlocutor.

A expressão tchê é conhecida e amplamente usada no falar do gaúcho. A explicação para a origem dessa palavra é diversa. Segundo alguns historiadores, provém das línguas ou dialetos indígenas das tribos que habitavam a região do Pampa ${ }^{3}$ (Rio Grande do Sul, Uruguai e Argentina), podendo significar "homem", "amigo", "gente”, tu”. Outra versão seria a de que era utilizada pelos espanhóis colonizadores da região do Pampa: para se referirem a outra pessoa, usavam interjeições religiosas como "criatura de Deus" ou "menino do céu", do latim caelestis (se lê tchelestis) que significa “do céu”, a qual os espanhóis passaram a abreviar para tche $\hat{e}^{4}$. Para o nosso estudo importa o uso desta expressão que, na linguagem em uso, pode expressar admiração ou espanto, se bom ou ruim, ou um chamamento. Essa cultura se manteve ao longo dos anos na língua do gaúcho, que ainda usa o tchê nas diversas situações discursivas do seu cotidiano. Para Bakhtin (1997), a história da língua está intrinsicamente

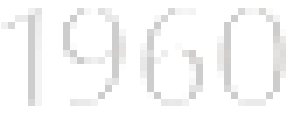

\footnotetext{
${ }^{3}$ Informação extraída do site < http://regionalismogaucho.weebly.com/expressatildeo-tchecirc.html $>$ que discute como surgiu a expressão tchê.

${ }^{4}$ Informação extraída do site < http://www.portaldasmissoes.com.br/site/view/id/1263/tche...-o-que-significaesta-expressao!.html > que discute como surgiu a expressão tchê.
}

Linguagens \& Cidadania, v. 19, jan./dez., 2017. 


\section{Singuagens}

ligada à história da sociedade; compreendemos que a formação histórica do povo gaúcho contribui para a sua forma peculiar na língua regional.

Bakhtin identifica os diálogos orais, sejam eles "linguagem das reuniões sociais, dos círculos, da linguagem familiar, cotidiana, linguagem sociopolítica, filosófica, etc." (BAKHTIN, 1997, p. 285) como gêneros do discurso primário, a linguagem em uso.

A partir do momento em que os gêneros do discurso secundário incorporam uma expressão ao seu discurso, sendo ele mais complexo, como explica Bakhtin, estes "aparecem em circunstâncias de uma comunicação cultural, mais complexa e relativamente mais evoluída" (1997, p. 281). Assim, a expressão regional gaúcha tchê passou a ganhar novos nuances, portanto, ao utilizar a expressão tchê na peça publicitaria PepsiTchêe, a marca de refrigerante busca "à sua maneira de participar ativamente de esferas de produção, circulação e recepção" (BRAIT, 2006, p. 13).

O refrigerante está presente em todos os momentos de alegria, comemoração, amizade e tristeza assim como a expressão tchê. Ao enunciar PepsiTchê, o interlocutor constrói uma relação dialógica entre enunciados, o gaúcho conhecedor da sua cultura entende o tchê nas diversas esferas discursivas e reconhece seu significado, pois só a palavra não é completa, somente "quando adquire uma autoria e ganha um acabamento, transforma-se em enunciado" (BAKHTIN, 1992, apud FIORIN, 2006, p. 169), assim tomando forma e produzindo sentido.

A primeira fábrica da Pepsi no Brasil foi instalada no Rio Grande do Sul em $1950,{ }^{5}$ na qual o proprietário Heitor Pires investiu pesado em marketing, fazendo com que os gaúchos acreditassem que a bebida era um produto local $^{6}$. O gaúcho tem uma relação de amor muito forte pelo Rio Grande do Sul, a história de lutas e revoluções que levaram o gaúcho a defender seu território contribuíram na construção deste sentimento, que passou a ser reforçada pelas criações literárias. Em virtude disso, o gaúcho valoriza muito o que é dele num sentido de pertencimento, por isso o rio-grandense tem essa proximidade e relação de

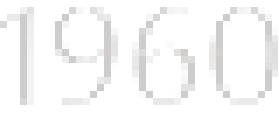

\footnotetext{
${ }^{5}$ Informação obtida no site da empresa Pepsico / Brasil sobre a história da marca, disponível em < http://www.pepsico.com.br/quem-somos/nossa-historia $>$.

${ }^{6}$ Informação extraída do site < https://pt.wikipedia.org/wiki/Pepsi $>$, que fala um pouco da história da Pepsi no Brasil.
} 


\section{S Linguagens}

amor pela Pepsi, com seu início aqui no estado e toda essa história de envolvimento do povo com o refrigerante, marcam essa relação.

A página de abertura do hotsite ${ }^{7}$, objeto deste estudo, apresenta um chamamento "Quando a paixão é verdadeira, a gente fala na lata" -, entendendo o sentido conotativo da expressão "fala na lata", que se refere a uma expressão usada pelos gaúchos quando querem dizer a verdade "na cara" de alguém. O discurso publicitário a incorpora para falar da paixão do povo gaúcho pelo refrigerante. Como vemos, o gênero discurso publicitário é constituído por muitas vozes que se cruzam e se completam. Fiorin explica que o dialogismo só existe entre discursos, sendo que se dá "um embate de dois discursos: o do locutor e o do interlocutor, o que significa que o dialogismo se dá sempre entre discursos" (FIORIN, 2006, p. 166).

Nessa perspectiva, o ouvinte recebe o discurso e passa a buscar por compreender o seu sentido para então adotar uma postura, "uma atitude responsiva ativa" (BAKHTIN, 1997, p. 290) ou uma "compreensão responsiva muda" (BAKHTIN, 1997, p. 291), sendo esta última mais própria do discurso publicitário, pois cedo ou tarde o que foi ouvido terá retorno com um eco no discurso ou no comportamento do ouvinte. Sendo este ouvinte um possível consumidor do refrigerante Pepsi, ao ouvir o chamamento "quando a paixão é verdadeira a gente fala na lata" ou o slogan PepsiTchê, passa a adotar uma postura que, na expectativa da marca, seja a identificação identitária do gaúcho com o refrigerante, que teve seu início no Brasil através da instalação da primeira fábrica no Rio Grande do Sul. O anunciante espera então uma resposta de concordância.

O enunciado pelo locutor, PepsiTchê, não é o primeiro enunciado, este já vem carregado de discursos anteriores, sendo a Pepsi um refrigerante de grande apreciação dos gaúchos. Tchê, expressão regional muito usada e que já constituiu outros discursos, é o que Bakhtin denomina "um elo da cadeia complexa de outros enunciados" (BAKHTIN, 1997, p. 178). O discurso publicitário também comporta não só enunciados anteriores, como explica

\footnotetext{
7 O hotsite, criado exclusivamente para a peça publicitária PepsiTchê, apresenta página inicial com o chamamento "Quando a paixão é verdadeira a gente fala na lata". Também apresenta as 13 latas feitas exclusivamente para a campanha publicitária da Semana Farroupilha e uma música dedicada aos gaúchos falando sobre sua paixão pela Pepsi. Disponível em < http://www.pepsibrasil.com.br/tche/\#/lata-portuga $>$.
}

Linguagens \& Cidadania, v. 19, jan./dez., 2017. 


\section{S Linguagens}

Fiorin, pois "o enunciado está relacionado não só aos que o precedem, mas também aos que lhe sucedem na cadeia da comunicação verbal" (FIORIN, 2006, p. 178). Compreendemos que a reação do possível consumidor do refrigerante é considerada, na constituição do discurso, a resposta ao discurso da peça publicitária, o que, por sua vez, também é uma das vozes a compor o discurso.

As práticas discursivas dos gêneros do discurso publicitário têm como intuito vender um produto, e com esta intencionalidade o discurso do refrigerante Pepsi buscou escolher determinados recursos lexicais para compor o conteúdo de seu discurso, dando sentido a ele. O tchê para o gaúcho é como uma marca que o define e o aproxima dos demais, de modo que o enunciado "adquire sentido definitivo somente dentro desse todo" (BAKHTIN, 1997, p. 307). "Nas condições concretas, delimitadas da comunicação verbal" (p. 307), é possível compreender o que o locutor quer-dizer; então o enunciado PepsiTchê passa a assumir sentido. Somente compreendendo a relação de paixão do gaúcho pelo Rio Grande do Sul, seus costumes, tradições, de seu jeito peculiar de falar e se expressar, e também dessa relação tão próxima do povo gaúcho com a Pepsi, é possível entender o valor de sentido que a expressão produz no enunciado do discurso publicitário PepsiTchê.

\section{CONSIDERAÇÕES FINAIS}

O presente estudo teve como objetivo demonstrar que as escolhas dos elementos discursivos propiciam uma imagem do produto próxima à imagem do possível consumidor. Para discutir o tema, analisamos a peça publicitária PepsiTchê, embasados nos estudos do Círculo de Bakhtin. Esta é uma pesquisa que integra um projeto denominado "Discurso e produção de sentidos: um olhar para os gêneros produzidos pela mídia", coordenado pela Professora Andrea Reginatto, registrado no GAP/CAL.

É possível dizer que o discurso publicitário em estudo busca uma relação dialógica com o seu interlocutor, tendo em vista as práticas sociais e discursivas do povo gaúcho que assimila e compreende o enunciado PepsiTchê como algo próximo de si. Reforçamos a ideia de que as escolhas lexicais interferem na força argumentativa do discurso publicitário, visto que a análise em questão observou que a escolha da expressão regional gaúcha tchê foi estrategicamente escolhida para propiciar uma proximidade do povo gaúcho com a marca 


\section{S. Linguagens}

Pepsi devido à importância dessa expressão, que em diversos contextos discursivos é usado para demonstrar o estado de espírito de seu locutor.

Conforme discutido anteriormente neste estudo, o gênero do discurso publicitário tem a expectativa de obter uma resposta/adesão do seu interlocutor, por isso o enunciado PepsiTchê busca nessa relação dialógica uma identificação identitária de seu interlocutor, possível consumidor do refrigerante, reiterando-a com a marca. $\mathrm{O}$ exposto acima demonstra como o discurso publicitário interage de acordo com a cultura do seu possível consumidor, o que justifica os estudos e análises das práticas do gênero do discurso publicitário.

A temática regionalista tem sido recorrente na publicidade de muitas marcas e acaba construindo um mecanismo de aproximação com o consumidor. Ao focar na cultura gaúcha, a marca do refrigerante Pepsi busca este vínculo com seu possível consumidor, portanto, é pertinente analisarmos e compreendermos as condições de produção do discurso publicitário regional ao considerar sua relevância social e mercadológicas.

\section{REFERÊNCIAS BIBLIOGRAFICAS}

BAKHTIN, M. Estética da criação verbal. Tradução: Maria Emstantina Galvão G. Pereira; revisão da tradução: Marina Appenzellerl. 2.ed.São Paulo: Martins Fontes, 1997.

BRAIT, B. (org.). Bakhtin: outros conceitos-chave. São Paulo: Contexto, 2006.

Bakhtin, dialogismo e construção de sentido. 2.ed. rev. Campinas, São Paulo: Editora da Unicamp, 2005.

FIORIN, J. L. Interdiscursividade e intertextualidade. In: BRAIT, B. (org.). Bakhtin: outros conceitos-chave. São Paulo: Contexto, 2006.

GIL, A. C. Métodos e técnicas de pesquisa social. 6.ed. São Paulo: Atlas, 2008.

PEPSICO. Disponível em: <http://www.pepsico.com.br/quem-somos/nossa-historia $>$. Acesso em: 1 jun. 2017.

Linguagens \& Cidadania, v. 19, jan./dez., 2017. 